\title{
The Prevalence of Hypertension during Ramadan
}

\section{Othman N1, Mohamad Soki NAB ${ }^{1}$ and Jamaludin TSS ${ }^{2 *}$}

${ }^{1}$ Kulliyyah of Nursing, International Islamic University Malaysia, Malaysia

${ }^{2}$ Department of Critical Care Nursing, International Islamic University Malaysia, Malaysia

*Corresponding author: Thandar Soe Sumaiyah Jamaludin, Department of Critical care

\section{Research Article}

Volume 3 Issue 4

Received Date: June 20, 2019

Published Date: July 02, 2019

DOI: $10.23880 /$ nhij-16000194

Nursing, Kulliyyah of Nursing, International Islamic University Malaysia, Kuantan Campus, 25250 Pahang, Malaysia, Tel: +6016-6092641; Email: sumaiyah@iium.edu.my

\section{Abstract}

Objective: This study was aimed to identify the prevalence of hypertension during the month of Ramadan in Kuantan as well as to compare the mean differences of blood pressure with pre, during and post Ramadan.

Methods: A retrospective cohort study by using purposive sampling with sample size of 66 hypertensive patients at Medical Outpatient Department (MOPD), Hospital Tengku Ampuan Afzan (HTAA), Kuantan was conducted. The data collection form was used as a research instrument to obtain data from hospital record. The data was analysed by using SPSS version 22 in term of descriptive analysis (frequency and percentage), and T-test for the significant differences.

Results: The majority of participant's age from 61 to 70 years old (34.8\%). For BMI, about 43 participants (65.2\%) were overweight or obese and the remaining 34.8\% were in normal BMI. Besides, about 30.0\% were smokers. The prevalence of hypertension can be divided into two which are systolic blood pressure and diastolic blood pressure. About $66.7 \%$ participants were affected at systolic area. In addition, about 16.7\% participants were affected at diastolic area. For independent T-test, there was no significant differences of systolic blood pressure and fasting with p-value 0.53. Besides, there was no significant differences of diastolic blood pressure and fasting with p-value 0.60. Furthermore, for paired Ttest, there were significant differences in mean of blood pressure between pre, during and post Ramadan with $\mathrm{p}$-value 0.00 .

Conclusion: Prevalence of hypertension during Ramadan can be indicator to prevent hypertension as well as to promote awareness to other people. Hence, the health care provider can educate people about modified diet or fasting can help in reducing the case of cardiovascular disease.

Keywords: Hypertension; Prevalence; Fasting 


\section{Nursing \& Healthcare International Journal}

Abbreviations: MOPD: Medical Outpatient Department; HTAA: Hospital Tengku Ampuan Afzan; IIUM: International Islamic University Malaysia; NMRR: National Medical Research Registered; MREC: Malaysia Registered Ethics Committee.

\section{Introduction}

Hypertension is known as the high blood pressure that defines as a condition in which the blood vessels have constantly raised pressure [1]. Additionally, hypertension has been identified as one of the major risk factors for non-communicable disease such as heart failure, ischemic heart disease, stroke as well as renal disease [2]. Hypertension also labelled as "silent killer" by certain people due to the CVD [1,3]. Hypertension in the developed countries and the developing countries also has been burden disease as well as the greatest threat to health care system. In Malaysia, the prevalence of hypertension was $30.3 \%$ that including the diagnosed and undiagnosed hypertension in 2015. Ramadan fasting is people are restrained from eating and drinking starting from dawn to sunset. In United Arab Emirates (UAE), the study about hypertension and fasting (Ramadan) reveals that there was significant reduction for blood pressure but other study in Iran mentioned that there were no significant difference for blood pressure.

Hence, it is importance to health care provider to know about the rising rates of hypertension in order to educate people about the risk factors of hypertension as well as encourage people to control or modified their current lifestyle before or after getting hypertension. Thus, this study aimed to identify the prevalence of hypertension during the month of Ramadan in Kuantan.

\section{Materials and Methods}

\section{Study Setting, Population and Sample Size}

A retrospective cohort study was used to identify the prevalence of hypertension during Ramadan in 2017. This study was conducted in Medical Outpatient Department (MOPD), Hospital Tengku Ampuan Afzan (HTAA), Kuantan, Pahang, Malaysia. The total population of hypertensive patients that came to MOPD during Ramadan was 79 people. The sampling method adopted in this study was purposive sampling and a total of 66 hypertensive patients' record was collected from MOPD. The Raosoft formula was used to calculate the sample size.

\section{Inclusion and Exclusion Criteria}

The hypertensive patients in both genders, the blood pressure record during Ramadan from 26 May 2017 until 24 Jun 2017, three months before Ramadan (preRamadan) from 1 March 2017 until 25 May 2017 and three months after Ramadan (post Ramadan) from 25 Jun 2017 until 15 September 2017, the reading scale for high blood pressure $\geq 140 \mathrm{mmHg}$ and $\geq 90 \mathrm{mmHg}$ were included in this study. Pregnant women, fever patients and renal patients were excluded in this study.

\section{Data Collection and Statistical Analysis}

The data was collected from the patients' record by using data collection form within March 2017 until September 2017. A checklist that included in data collection form were socio-demographic data and the blood pressure measurement.

The data was analysed by using SPSS version 22 . Independent T-test was used for significant differences between blood pressure and fasting groups, while paired T-test was used for comparison of the significant difference of hypertension between pre, during and post Ramadan.

\section{Ethical Approval}

The study was ethically approved by the International Islamic University Malaysia (IIUM) Research Ethics Committee (IREC), National Medical Research Registered (NMRR) and Malaysia Registered Ethics Committee (MREC).

\section{Results}

Among the 66 participants, majority of participants were female and the age range of 61 to 70 years old. There were 43 participants were overweight or obese. Based on smoking status, there were 20 participants were smoker and 46 participants do not smoke as shown in Table 1. 


\section{Nursing \& Healthcare International Journal}

\begin{tabular}{|c|c|c|c|}
\hline $\mathrm{N}=66$ & Variables & Frequency (n) & Percentage (\%) \\
\hline \multirow{6}{*}{ Age } & $21-30$ & 3 & 4.5 \\
\hline & $31-40$ & 6 & 9.1 \\
\hline & $41-50$ & 12 & 18.2 \\
\hline & $51-60$ & 16 & 24.2 \\
\hline & $61-70$ & 23 & 34.8 \\
\hline & $71-80$ & 6 & 9.1 \\
\hline \multirow{2}{*}{ Gender } & Male & 25 & 37.9 \\
\hline & Female & 41 & 62.1 \\
\hline \multirow{4}{*}{ Race } & Malay & 41 & 62.1 \\
\hline & Chinese & 11 & 16.7 \\
\hline & Indian & 13 & 19.7 \\
\hline & Others & 1 & 1.5 \\
\hline \multirow{2}{*}{ BMI } & Normal & 23 & 34.8 \\
\hline & Overweight/obese & 43 & 65.2 \\
\hline \multirow{4}{*}{ Occupational } & Not working & 21 & 31.8 \\
\hline & Government servant & 23 & 34.8 \\
\hline & Private servant & 12 & 18.2 \\
\hline & Self-employed & 10 & 15.2 \\
\hline \multirow{4}{*}{ Educational Level } & Primary School & 5 & 7.6 \\
\hline & Secondary School & 16 & 24.2 \\
\hline & Certificate/Diploma & 36 & 54.5 \\
\hline & Bachelor/Master/PhD & 9 & 13.6 \\
\hline \multirow{2}{*}{ Smoker } & Yes & 20 & 30.3 \\
\hline & No & 46 & 69.7 \\
\hline
\end{tabular}

Table 1: Socio-demographic data and the factors related to hypertension.

The result also showed that $66.7 \%$ of participants had higher systolic blood pressure, meanwhile, there were
$16.7 \%$ participants having higher diastolic blood pressure as shown in Table 2.

\begin{tabular}{|c|c|c|c|}
\hline \multicolumn{2}{|c|}{} & Frequency (n) & Percentage (\%) \\
\hline \multirow{2}{*}{ Systolic Blood Pressure } & High (>140) & 44 & 66.7 \\
\cline { 2 - 4 } & Normal (100-139) & 22 & 33.3 \\
\hline \multirow{2}{*}{ Diastolic Blood Pressure } & High (>90) & 11 & 16.7 \\
\cline { 2 - 4 } & Normal (50-89) & 55 & 83.3 \\
\hline
\end{tabular}

Table 2: The prevalence of hypertension during Ramadan $(\mathrm{N}=66)$.

There was not a significant difference of systolic blood pressure in the fasting (Mean 149.84, $\mathrm{SD}=22.91$ ) and no fasting (Mean 146.26, $\mathrm{SD}=19.93$ ) conditions; $\mathrm{t}(64)=$ $0.631, \mathrm{p}=0.53$. In addition, there was not a significant difference of diastolic blood pressure in the fasting (Mean 76.23, $\mathrm{SD}=12.958$ ) and no fasting (Mean 77.91, $\mathrm{SD}=11.786$ ) conditions; $\mathrm{t}(64)=-0.518, \mathrm{p}=0.606$ by using independent T-test as shown in Table 3.

\begin{tabular}{|c|c|c|c|c|c|}
\hline Variables & Fasting & Mean & $\begin{array}{c}\text { Standard Deviation } \\
\text { (SD) }\end{array}$ & t-statistic (df) & ${ }^{*}$ p-value \\
\hline \multirow{2}{*}{ Systolic BP } & Yes & 149.84 & 22.914 & \multirow{2}{*}{0.631} & \multirow{2}{*}{0.53} \\
\hline & No & 146.26 & 19.932 & & \\
\hline \multirow{2}{*}{ Diastolic BP } & Yes & 76.23 & 12.958 & \multirow{2}{*}{-0.518} & \multirow{2}{*}{0.606} \\
\hline & No & 77.91 & 11.786 & & \\
\hline
\end{tabular}

Table 3: The significant difference between blood pressure and fasting group $(\mathrm{N}=66)$. 


\section{Nursing \& Healthcare International Journal}

The result showed that there were significant differences in mean of blood pressure between preRamadan (Mean 72.09, SD= 16.438), during Ramadan
(Mean 71.77, $\mathrm{SD}=17.464$ ) and post Ramadan (Mean $71.63, \mathrm{SD}=17.142$ ) which concluded that $p$-value of 0.000 by using paired T-test as shown in Tables 4-6.

\begin{tabular}{|c|c|c|c|c|}
\hline Variables & Pre-Ramadan mean (SD) & During Ramadan mean (SD) & ${ }^{*}$ t-statistic (df) & ${ }^{*}$ p-value \\
\hline Blood pressure & $72.09(16.438)$ & $71.77(17.464)$ & $34.50(65)$ & 0.00 \\
\hline
\end{tabular}

Table 4: The comparison of hypertension between pre and during Ramadan $(\mathrm{N}=66)$.

\begin{tabular}{|c|c|c|c|c|}
\hline Variables & Pre-Ramadan mean (SD) & Post Ramadan mean (SD) & ${ }^{*}$ t-statistic (df) & p-value \\
\hline Blood pressure & $72.09(16.438)$ & $71.63(17.142)$ & $34.79(65)$ & 0.00 \\
\hline
\end{tabular}

Table 5: The comparison of hypertension between pre and post Ramadan (N=66).

\begin{tabular}{|c|c|c|c|c|}
\hline Variables & During Ramadan mean (SD) & Post Ramadan mean (SD) & ${ }^{*}$ t-statistic (df) & p-value \\
\hline Blood pressure & $71.77(17.464)$ & $71.63(17.142)$ & $33.67(65)$ & 0.00 \\
\hline
\end{tabular}

Table 6: The comparison of hypertension between during and post Ramadan (N=66).

\section{Discussion}

The data showed that people age between 41 and 80 years old had higher percentage $(86.4 \%)$ compare to 21 to 40 years old $(13.6 \%)$. The recent study stated that, prevalence of hypertension increased with increasing age $[4,5]$. In addition, the aging processes cause the changes in blood vessels that can lead to high blood pressure [5]. There were $65.7 \%$ of participants were overweight or obese in BMI. The finding in other study revealed that overweight and obese participants had high prevalence of hypertension [2]. The smoking status in the finding revealed that only $30.3 \%$ of participants were smokers. The previous study mentioned that smoking can cause stiffness in the blood vessels and can lead to hypertension associated with the aging process [6]. The prevalence of hypertension in this study was divided into two which were systolic blood pressure (66.7\%) and diastolic blood pressure $(16.7 \%)$. The finding revealed that the prevalence of hypertension among people in Kuantan still high due to the fact that they might be not aware about the benefits of changing eating habit can help in reducing the blood pressure.

By using independent T-test, there was no significant differences between fasting groups with systolic blood pressure with p-value were 0.53 . In addition, there was no significant a difference between fasting groups with diastolic blood pressure with p-value was 0.60 . From previous research, the finding reported that there were no significant changes in blood pressure during Ramadan fasting $[7,8]$. As mentioned by Ernsberger, et al. and Perk, et al. blood pressure during intermittent fasting showed no changes. As hypothesized, paired T-test has proved that there was a significant difference in mean with $\mathrm{p}$ - value was 0.00 of pre-Ramadan, during Ramadan and post Ramadan. When comparison of mean was done for preRamadan, during Ramadan and post Ramadan, it showed that the blood pressure mean was slightly reduced. This may be because of fasting that helps hypertensive participants to lower their blood pressure by controlling their diet as well as consuming the medication. The previous study stated significant reduction in systolic and diastolic blood pressure due to Ramadan fasting [9]. Besides that, the recent study revealed that there was a significant decrease in systolic and diastolic blood pressure as well as heart rate [10-12].

\section{Conclusion}

The prevalence of hypertension during Ramadan was still high in this study. The finding of this study gives a baseline data for health care professional especially nurses to plan the primary intervention in preventing high blood pressure among adults. The finding of this study also can be a good source for nurses to inculcate the elements in providing the best medium to promote health awareness in order to avoid more dangerous complication such as cardiovascular disease in hypertensive patients. Lastly, this study finding will help nurses to educate hypertensive patients on modification of diet and fasting can help them to prevent from further complication.

\section{Limitation}

There were several limitations in this study. There was a time restriction for collecting data related to waiting for approval from several ethical committees and related authorities. The small sample size that was used also one 


\section{Nursing \& Healthcare International Journal}

of the limitations because not all hypertensive patients will go to MOPD to check their blood pressure. In addition, it was quite challenging when collecting the data from secondary resource because not all the data was available.

\section{Recommendations}

Therefore, it is recommended in the future to conduct a study and control the bias or co-founder. Future study should be conducted with bigger sample size. Hence, the participants should be recruited among a larger number of hospitals or health institutions to meet the larger sample size. It does not only involve one hospital but even more. It can involve health clinic because most people go there to get their check-up. As the higher participants can be recruited from larger population size, thus the results will be wider and provide information about the current condition of hypertensive patients as overall. Recommended to do prospective cohort study or crosssectional study in future. When do prospective cohort study, a follow up with participants should be done to provide better data from participants because researcher can know either they are fasting or not.

\section{Acknowledgements}

We would like to express our sincere appreciation to all studied participants who participated in this study. Sincere thanks to International Islamic University Malaysia (IIUM) for funding this study (RIGS16-1400304).

\section{References}

1. WHO (2013) A Global Brief of Hypertension. World Health Organization, pp: 40.

2. Abdul Razak S, Daher AM, Ramli AS, Ariffin F, Mazapuspavina MY, et al. (2016) Prevalence, awareness, treatment, control and socio demographic determinants of hypertension in Malaysian adults. BMC Public Health 16: 351.

3. Bhatt D, Sharma S, Gupta R, Sinha DN, Mehrotra R, et al. (2017) Predictors of Hypertension among Nonpregnant Females Attending Health Promotion Clinic with Special Emphasis on Smokeless Tobacco: A Cross-Sectional Study. Biomed Res Int 2017: 5.
4. Demisse AG, Greffie ES, Abebe SM, Bulti AB, Alemu S, et al. (2017) High burden of hypertension across the age groups among residents of Gondar city in Ethiopia: a population based cross sectional study. BMC Public Health 17(1): 647.

5. Lloyd Jones DM, Levy D (2013) Epidemiology of Hypertension. In: Black HR (Eds.), Hypertension A Companion to Braunwald's Heart Disease 2 ${ }^{\text {nd }}(E d n$.$) ,$ Philadelphia: Elsevier.

6. Saladini F, Benetti E, Fania C, Mos L, Casiglia E, et al. (2016) Effects of smoking on central blood pressure and pressure amplification in hypertension of the young. Vasc Med 21(5): 422-428.

7. Maryam AN, Maryam S (2016) Effects of Ramadan Fasting on Blood Pressure in Hypertensive Patients: A Systematic Review. Journal of Fasting and Health 4(1): 17-21.

8. Nematy M, Alinezhad-Namaghi M, Rashed MM, Mozhdehifard M, Sajjadi SS, et al. (2012) Effects of Ramadan fasting on cardiovascular risk factors: a prospective observational study. Nutrition Journal 11: 69.

9. M S, Ah SA, Sr S, Km B (2014) Effect of Ramadan Fasting on Body Weight, (BP) and Biochemical Parameters in Middle Aged Hypertensive Subjects: An Observational Trial. J Clin Diagn Res 8(3): 16-18.

10. Erdem Y, Özkan G, Ulusoy S, Arici M, Turkish Society of Hypertension and Renal Diseases, et al. (2018) The effect of intermittent fasting on blood pressure variability in patients with newly diagnosed hypertension or prehypertension. J Am Soc Hypertens 12(1): 42-49.

11. Akter SFU, Fauzi ARM, Nordin MS, Satwi S, Mohamed A, et al. (2010) Prevalence of cardiovascular risk factors in a selected community at Kuantan, Pahang, Malaysia. International Journal of Medicine and M edical Sciences 2(10): 322-328.

12. Viera AJ, Hawes EM (2016) Management of mild hypertension in adults. BMJ 355: i5719. 